\title{
Sentinel lymph node mapping in liver resection for colorectal liver metastases
}

Running head: sentinel lymph node and liver metastases

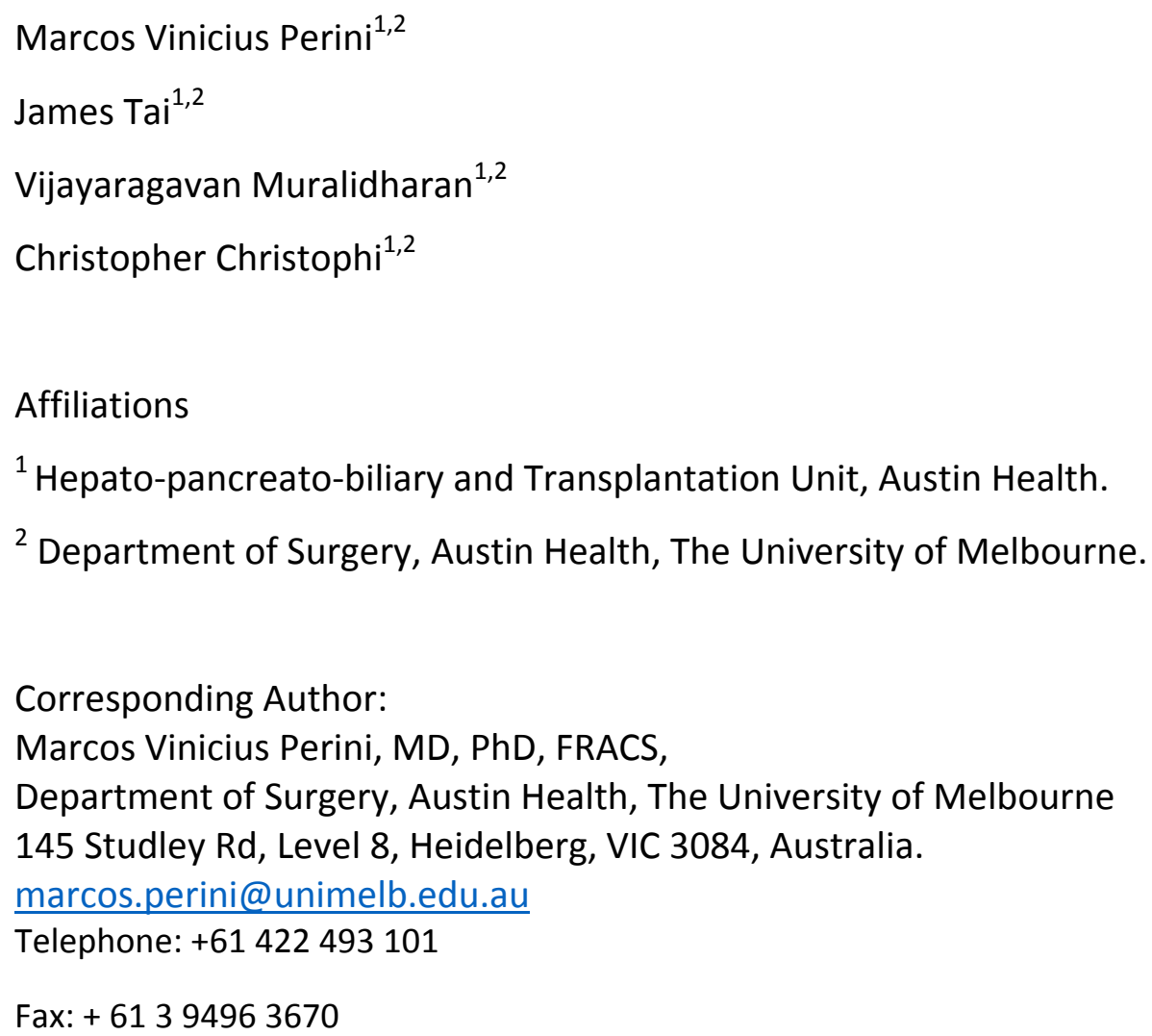

Key words: hepatectomy, colorectal cancer, sentinel lymph node, technique, surgery

Number of figures: 02

Number of words excluding references and legends: 780

This is the author manuscript accepted for publication and has undergone full peer review but has not been through the copyediting, typesetting, pagination and proofreading process, which may lead to differences between this version and the Version of Record. Please cite this article as doi: 10.1111/ans.14405

This article is protected by copyright. All rights reserved. 


\section{Introduction}

Recurrence after resection of colorectal liver metastases (CRLM) happens in up to $70 \%$ of the cases ${ }^{1}$. Evidence suggests that changes to the lymphatic system in a subgroup of patients with CRLM plays a significant role in lymphatic dissemination, both within the liver and extrahepatic ${ }^{2}$. Survival advantage may occur with resection of lymph nodes (LN) in conjunction with hepatectomy since microscopic hilar nodal disease may be present in $20 \%$ of cases, carrying a worse prognosis ${ }^{3}$. Identifying high-risk patients for local nodal recurrence could have the potential benefit of offering them improved staging and consideration for hilar lymphadenectomy ${ }^{1}$.

Sentinel lymph node mapping (SLNM) may identify the appropriate nodal group to be sampled in conjunction with liver resection (LR). This minimizes lymphadenectomy to the involved nodal chain, reducing morbidity.

This article describes SLNM in CRLM using a dual technique developed in our Unit to identify the most likely nodal chain of having metastatic disease based on tumour location.

\section{Case report}

This article is protected by copyright. All rights reserved. 
A 70y old male patient with synchronous colorectal cancer and liver metastases was referred for surgical treatment. He presented with a colorectal cancer $10 \mathrm{~cm}$ from the anal verge and a liver metastasis near the right hepatic vein. He underwent neoadjuvant chemotherapy with FOLFOX with good response, hence surgical resection was proposed. He underwent a laparoscopic low anterior resection (moderately-differentiated adenocarcinoma of the rectum showing 3 out of 49 positive resected nodes with clear margins - T2N1) and, in a second procedure, a right hemihepatectomy. At the time of the $L R$, parenchyma-sparing liver resection (metastasectomy) was not possible because the tumour was abutting the right hepatic vein (Figure 1) and a right hemihepatectomy was proposed to achieve clear margins. He was considered eligible for the SLNM protocol and consented accordingly.

No dissection was carried out around the IVC or hilum during the operation. Under intraoperative ultrasound-guidance, $2 \mathrm{ml}$ of patent blue die and $20-40 \mathrm{MBq}$ of ${ }^{99 \mathrm{~m}} \mathrm{Tc}$-rhenium sulphide colloid $/{ }^{99 \mathrm{~m}} \mathrm{Tc}$-antimony sulphide colloid was injected in four quadrants close to tumour. At 15 minutes and 30 minutes, the lymphatic nodal basins (porta hepatis, omental foramen, retroduodenopancreatic, hepatic artery, celiac trunk, caval and diaphragmatic nodes) were scanned with the gamma probe. The radioactivity at each lymphatic nodal basin was recorded and the sentinel node was considered "positive" if the gamma probe measurement was $>20 \%$ than that of the primary tumour. Figure 2 shows the blue die spread in the diaphragmatic area, however, no lymph node was seen/palpated in the demarcated area and all chains were considered negative. According to our protocol, 
sampling was to be performed when nodal tissue was identified in at least one of the methods (blue dye positive or $>20 \%$ of radiation activity compared to the primary tumour). No lymphadenectomy was then performed. Histology showed a $4.2 \mathrm{~cm}$ moderatelydifferentiated adenocarcinoma, clear of the resection margin by $2 \mathrm{~cm}$. Recovery was uneventful, however after six months he developed right side lung metastases and new liver lesions. He is currently on chemotherapy.

\section{Discussion}

Microscopic nodal disease poses a challenge in the management of CRLM. Conflicting data exist, with some surgeons proposing routine lymphadenectomy associated with the $\mathrm{LR}^{4}$ and others advocating that it is a marker of disseminated disease thus chemotherapy should be offered ${ }^{3}$. A selective approach is yet to be defined and robust $\underline{\text { data }}$ are not available to support the use of more aggressive strategies ${ }^{5,6}$.

The current case illustrates the technique of SLNM whereby a dual technique was used in the assessment of CRLM. The rationale for this technique is that microscopic nodal disease present at the time of the operation cannot be excluded by any imaging procedure and intraoperative assessment by surgeons (palpation, consistency, size and shape) is not reliable, with a predictive value of $39 \%^{7}$.

The advantages of this approach are yet unproven and we expect that selective lymphadenectomy could be another surgical tool in the treatment of patients with high likelihood of nodal recurrence. Lymphatic spread of lesions located deep in the liver, close 
to hepatic veins and distant from the portal triad, tends to happen through the lymphatic channels surrounding the hepatic vein and could explain why we did not identify any hilar nodal disease associated with the inking of diaphragmatic lymphatic vessels, running from the liver towards the right hemidiaphragm ${ }^{8}$. It is known that collagen fibers in the space of Disse are continuous with those around the central lobular vein, which, in turn, increase in number toward the sublobular vein and the hepatic vein and coalesce into those around the $I V C^{9}$. Moreover, the liver metastasis was located close to the right hepatic vein, which could also explain the appearance of new lung and mediastinal metastases ${ }^{6}$. The present case raises further questions regarding liver lymphatic drainage and highlights the lack of understanding about this interesting topic.

\section{References:}

1. Oussoultzoglou E, Romain B, Panaro F, et al. Long-term survival after liver resection for colorectal liver metastases in patients with hepatic pedicle lymph nodes involvement in the era of new chemotherapy regimens. Ann Surg 2009; 249(6):87986.

2. Vellinga TT, Kranenburg $\mathrm{O}$, Frenkel $\mathrm{N}$, et al. Lymphangiogenic Gene Expression Is Associated With Lymph Node Recurrence and Poor Prognosis After Partial Hepatectomy for Colorectal Liver Metastasis. Ann Surg 2017.

3. Bennett JJ, Schmidt CR, Klimstra DS, et al. Perihepatic lymph node micrometastases impact outcome after partial hepatectomy for colorectal metastases. Ann Surg Oncol 2008; 15(4):1130-6.

4. Jaeck $D$, Nakano $H$, Bachellier $P$, et al. Significance of hepatic pedicle lymph node involvement in patients with colorectal liver metastases: a prospective study. Ann Surg Oncol 2002; 9(5):430-8. 
5. Kane JM, 3rd, Kahlenberg MS, Rodriguez-Bigas MA, et al. Intraoperative hepatic lymphatic mapping in patients with liver metastases from colorectal carcinoma. $A m$ Surg 2002; 68(9):745-50.

6. Christophi C, Nguyen L, Muralidharan V, et al. Lymphatics and colorectal liver metastases: the case for sentinel node mapping. HPB (Oxford) 2014; 16(2):124-30.

7. Grobmyer SR, Wang L, Gonen $M$, et al. Perihepatic lymph node assessment in patients undergoing partial hepatectomy for malignancy. Ann Surg 2006; 244(2):2604.

8. Trutmann M, Sasse D. The lymphatics of the liver. Anat Embryol (Berl) 1994; 190(3):201-9.

9. Ohtani $Y$, Wang BJ, Poonkhum R, et al. Pathways for movement of fluid and cells from hepatic sinusoids to the portal lymphatic vessels and subcapsular region in rat livers. Arch Histol Cytol 2003; 66(3):239-52.

Disclosure:

The authors have no disclosure and haven't received any funding as well. 
Figure 1 - Pre-operative CT scan showing segment 7 liver lesion $(A)$ and its relationship with the right hepatic vein (B).

Figure 2: intra operative pictures after $30 \mathrm{~min}$ of peri-tumoral ultrasound guided blue dye and radiotracer injection. Note the black arrows showing lymphatic channels on the diaphragm and the white arrow (D) the tumour location. 


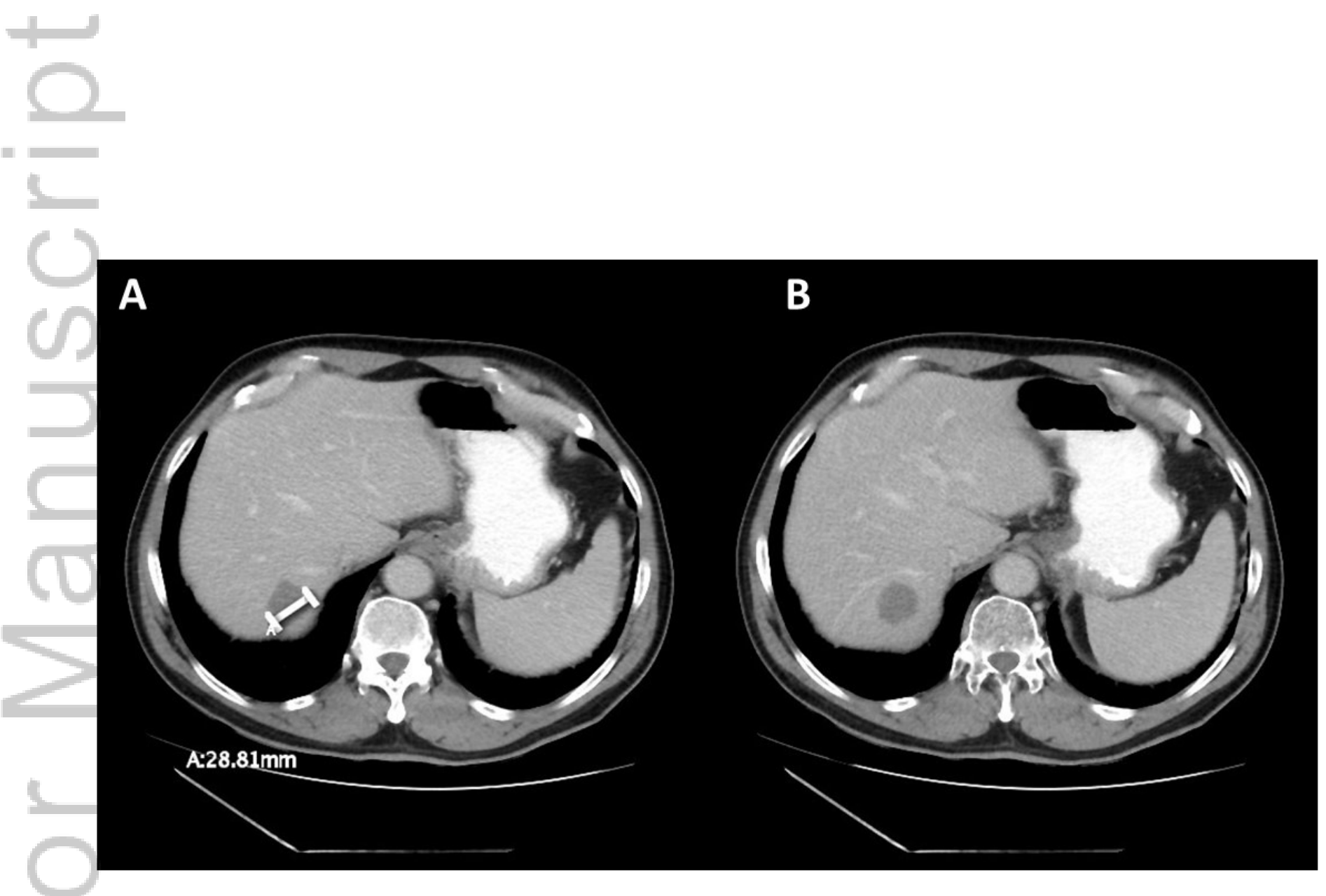

Figure 1 CT scan.jpg

This article is protected by copyright. All rights reserved. 


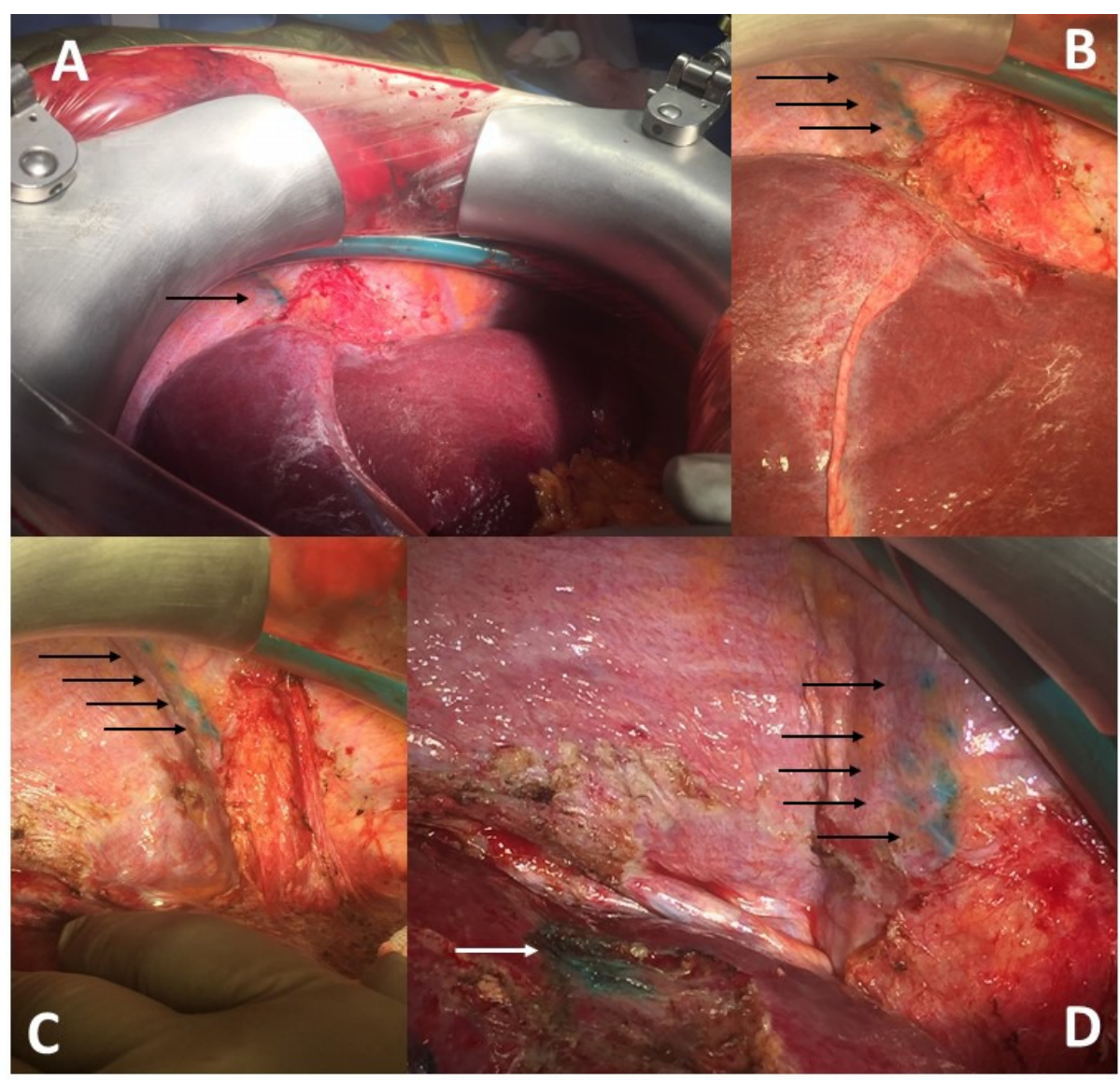

Figure 2 surgery with arrows 2.jpg

This article is protected by copyright. All rights reserved. 


\section{University Library}

\section{- M M N E R VA A gateway to Melbourne's research publications}

Minerva Access is the Institutional Repository of The University of Melbourne

Author/s:

Perini, MV;Tai, J;Muralidharan, V;Christophi, C

Title:

Sentinel lymph node mapping in liver resection for colorectal liver metastases

Date:

2019-07-01

Citation:

Perini, M. V., Tai, J., Muralidharan, V. \& Christophi, C. (2019). Sentinel lymph node mapping in liver resection for colorectal liver metastases. ANZ JOURNAL OF SURGERY, 89 (7-8), pp.978-980. https://doi.org/10.1111/ans.14405.

Persistent Link:

http://hdl.handle.net/11343/283572 